\title{
The photodegradation of Pyrromethene 567 and Pyrromethene 597 by Pyrromethene 546
}

\author{
Nobuaki Tanaka ${ }^{a}$, Wade N. Sisk ${ }^{\text {b,* }}$ \\ ${ }^{\mathrm{a}}$ Department of Environmental Science and Technology, Shinshu University \\ 4-17-1 Wakasato, Nagano, Nagano 380-8553, Japan \\ ${ }^{\mathrm{b}}$ Chemistry Department, University of North Carolina at Charlotte \\ 9201 University City Blvd., Charlotte, NC 28223-0001, USA \\ Tel: (704) 687-4433, Fax: (704) 687-3151 \\ E-mail: wsisk@email.uncc.edu
}

\begin{abstract}
The photo-destabilizing action of 1,3,5,7,8-pentamethylpyrromethene difluoroborate complex (PM546) on 1,3,5,7,8-pentamethyl-2,6-diethylpyrromethene difluoroborate complex (PM567) and 1,3,5,7,8-pentamethyl-2,6-di-t-butylpyrromethene difluoroborate complex (PM597) has been investigated. Acetonitrile solutions of PM567 and PM597 demonstrated accelerated photodegradation upon the addition of PM546; whereas the photodegradation rate of the corresponding $n$-hexane solutions remained invariant with respect to PM546 addition. The enhanced photodegradation rate is explained by electron transfer from PM567 and PM597 to PM546. A PM546 singlet oxygen $\left({ }^{1} \mathrm{O}_{2}, \mathrm{O}_{2}\left(\mathrm{a}^{1} \Delta_{\mathrm{g}}\right)\right)$ quenching rate constant of 3.86 $\pm 0.18(2 \sigma) \times 10^{7} \mathrm{dm}^{3} \mathrm{~mol}^{-1} \mathrm{~s}^{-1}$ is obtained from infrared phosphorescence measurements of $\mathrm{O}_{2}$ $\left(\mathrm{a}^{1} \Delta_{\mathrm{g}} \rightarrow \mathrm{X}^{3} \Sigma_{\mathrm{g}}{ }^{-}\right)$
\end{abstract}


Keywords: singlet oxygen, pyrromethene dyes, photostability, phosphorescence, quenching, electron transfer

\section{Introduction}

The photostability of organic dyes limits their practical applications to photonics where long lifetime and durability are required. Previous investigations have measured the photostabilities of organic dyes possessing high fluorescence quantum yields such as pyrromethene difluoroborate complexes (PM dyes) and perylene diimides [1-5]. Molecular oxygen $\mathrm{O}_{2}$ plays an important role in the photodegradation mechanism of dyes and pigments [6,7]. The photobleaching mechanism may depend on oxygen and the nature of the solvent. In the pursuit of higher laser damage thresholds and enhanced durability against photodegradation, a thorough investigation of the effect of additives on the photodegradation mechanism should be undertaken.

Ahmad et al. reported the photostability improvement of PM567/ethanol solutions and polymer dispersed PM567 by the addition of Coumarin 540 (C540) [8]. On the other hand, Jones reported fluorescence quenching of pyrromethene dye acetonitrile solutions by electron acceptors such as methyl viologen or pyromellitic dianhydride via electron transfer [9]. Electron transfer is one of the most fundamental reactions in chemistry and biology. A number of important processes including photosynthesis involve electron transfer. Even in systems where electron transfer is not energetically favorable in the ground state, photoexcitation would induce the reaction.

In this paper we report on the change in photodegradation rates of PM567 and PM597

solutions by PM546 addition following intense $532 \mathrm{~nm}$ laser irradiation. To better understand the role of PM546 in the photodegradation of PM567 and PM597, the singlet oxygen quenching rate constant of PM546 has been determined in acetonitrile solution. 


\section{Experimental}

Pyrromethenes 546, 567 and 597 were obtained from Exciton Inc. and used as received. Rose Bengal was obtained from Aldrich and used without any further purification. Acetonitrile (HPLC grade) and $n$-haxane (ultimAR grade) were obtained from Aldrich and Mallinckrodt,

respectively. The $2^{\text {nd }}$ harmonic of a Q-switched Nd:YAG laser (Continuum Surelite, 8 ns FWHM, $10 \mathrm{~Hz}$ ) was used as an excitation source.

Photostability experiments were carried out for $1.0 \times 10^{-5} \mathrm{~mol} \mathrm{dm}^{-3}$ acetonitrile solutions of PM597/PM546 and PM567/PM546 and for $1.0 \times 10^{-5} \mathrm{~mol} \mathrm{dm}^{-3} n$-hexane solutions of PM597/PM546 with varying PM546 concentration. Photodegradation was monitored by measuring absorption spectra with a Varian Cary 300 Bio uv-vis spectrophotometer following $532 \mathrm{~nm}$ irradiation. To accelerate photodegradation a laser fluence of $148.6 \mathrm{~mJ} \mathrm{~cm} \mathrm{culse}^{-1}$ was used to irradiate $1.5 \mathrm{ml}$ of the sample solution.

Fluorescence quenching of PM597 by PM546 in acetonitrile was measured using a Jobin Yvon Spex Fluorolog-3 spectrofluorimeter with a front-surface excitation emission geometry.

For singlet oxygen quenching measurements $3.0 \mathrm{ml}$ of $5.6 \times 10^{-5} \mathrm{~mol} \mathrm{dm}^{-3}$ rose bengal acetonitrile solutions with varying PM546 concentrations were excited at $532 \mathrm{~nm}$. The resulting $1270 \mathrm{~nm}$ phosphorescence attributed to $\mathrm{O}_{2}\left(\mathrm{a}^{1} \Delta_{\mathrm{g}} \rightarrow \mathrm{X}^{3} \Sigma_{\mathrm{g}}{ }^{-}\right)$was detected at right angles to the laser propagation and filtered by three high pass filters (Rolyn OG-5550, 65.1398, 65.1400) and a $1270 \mathrm{~nm}$ narrow bandpass filter (Spectrogon Filter N13-1270-010-8). The low laser intensity of $1.6 \mathrm{~mJ} \mathrm{~cm} \mathrm{~cm}^{-2}$ pulse $^{-1}$ ensures a linear phosphorescence response. The filtered infrared phosphorescence was imaged onto the active element $(0.5 \mathrm{~cm} \times 0.5 \mathrm{~cm})$ of a Judson germanium photodiode (J16D-M204-R05M-60) equipped with a preamplifier (PA-9-44) via a Herasil 1 inch f/1 lens. The photodiode output was collected and averaged over 20 laser pulses by a LeCroy 
$9350500 \mathrm{MHz}$ digital oscilloscope. The averaged phosphorescence decay profiles were stored on a personal computer. Three phosphorescence profiles were recorded for fresh solutions for each concentration.

Geometry optimizations of the $\mathrm{S}_{0}$ and $\mathrm{T}_{1}$ states of the $\mathrm{PM}$ dyes were performed using Becke's three-parameter hybrid density functional in combination with the Lee-Yang-Parr correlation functional (B3LYP) and Handy's pure density functional including gradientcorrected correlation (HCTH). All calculations were performed using Gaussian 03W [10].

\section{Results and discussion}

\subsection{Photostability of PM567 and PM597 in solution}

Fig. 1 shows a change in absorption spectra of PM597 in acetonitrile upon laser irradiation.

(Fig. 1)

The peaks due to PM597 decrease while absorbance increases and isosbestic points are observed near 300 and $430 \mathrm{~nm}$.

Relative absorbance changes of PM567/acetonitrile, PM597/acetonitrile and PM597/nhexane solutions are compared in Fig. 2.

(Fig. 2)

After 36,000 pump pulses a 34\% and 51\% decrease in absorbance was observed for acetonitrile solutions of PM567 and PM597, respectively. This degradation rate disparity may be attributed to the difference in the $532 \mathrm{~nm}$ absorption coefficients [3]. In contrast with the results in polar acetonitrile, a 14\% decrease in PM597 absorbance was observed in $n$-hexane. This is consistent with previous photostability studies [11]. The photostability of pyrromethene dyes in 
non-polar solvents exceeds that of the polar solvents. One possible explanation for the higher photodegradation rate in polar solvents is due to the contribution of an oxygen independent mechanism which was postulated to explain the enhanced photodegradation rate of PM567 thin films upon the application of an electric field [12].

$$
\begin{aligned}
& { }^{1} \mathrm{D}+\mathrm{h} v \rightarrow{ }^{1} \mathrm{D}^{*} \\
& { }^{1} \mathrm{D}^{*}+\mathrm{h} v \rightarrow{ }^{3} \mathrm{D}^{*} \\
& { }^{3} \mathrm{D}^{*}+\mathrm{D} \rightarrow\left[\mathrm{D}^{\bullet+}+\mathrm{D}^{\bullet-}\right] \\
& {\left[\mathrm{D}^{\bullet+}+\mathrm{D}^{\bullet-}\right] \rightarrow \mathrm{D}^{\bullet+}+\mathrm{D}^{\bullet-}} \\
& \mathrm{D}^{\bullet+}+\mathrm{D} \rightarrow \text { products } \\
& \mathrm{D}^{\bullet-}+\mathrm{D} \rightarrow \text { products }
\end{aligned}
$$

Polar solvents would achieve better stabilization of the free ions (Eq. (4)), thus resulting in more reaction products per unit time.

In a recent study of PM597 photodegradation in methanol dye photodegradation was observed to be $2^{\text {nd }}$ order with respect to PM597 concentration in accordance with Eq. (7) [5].

$$
\frac{[P M 597]_{0}}{[P M 597]}=1+[P M 597]_{0} k t
$$

In the present investigation, least-squares fits of acetonitrile and $n$-hexane solutions of PM597 photodegradation to Eq. (7) are shown in Fig. 3.

(Fig. 3)

The linear dependence of PM597/n-hexane solutions to Eq. (7) suggests a photodegradation rate that is $2^{\text {nd }}$ order with respect to concentration consistent with PM597/methanol photodegradation [5]. The nonlinear fit of PM597/acetonitrile solutions may be attributed to longer singlet oxygen lifetimes and/or faster ${ }^{1} \mathrm{O}_{2}$ quenching by PM597 in acetonitrile relative to hexane $[5,13,14]$. 
Fig. 4 shows the effect of $2.5 \times 10^{-5} \mathrm{~mol} \mathrm{dm}^{-3}$ PM546 addition on the photostability of $1.0 \times 10^{-5} \mathrm{~mol} \mathrm{dm}{ }^{-3}$ PM567 and PM597. Addition of PM546 resulted in significantly faster photodegradation of PM567 and 597 in acetonitrile.

(Fig. 4)

On the other hand in $n$-hexane, PM546 addition resulted in a nominal change in the photodegradation rate of PM597 and PM567. There is no significant decrease in absorbance of PM546. Fig. 5 compares the ratios of the absorbance of PM567 and PM597 in acetonitrile after 36,000 laser pulses for several PM546 concentrations, where $\mathrm{A}_{0}$ and A represent the absorbance in the absence and the presence of PM546 addition after 36,000 laser pulses.

(Fig. 5)

As the concentration of PM546 increases, the ratios $\mathrm{A}_{0} / \mathrm{A}$ monotonically increases.

In order to investigate the effect of oxygen, deoxygenated sample solutions were irradiated. Significant improvement in photostability is observed in Fig. 6. Under these conditions photooxidation via oxygen is inoperative, however accelerated photodegradation following PM546 addition occurs for acetonitrile samples under vacuum. Thus, other photodegradation mechanisms need to be considered.

(Figs. 6)

These alternative photodegradation mechanisms may involve the chemical reaction or complex formation between PM546 and PM597. Complex formation and chemical reaction were evaluated by analyzing the emission and absorption spectra. Fluorescence quenching of PM597 by PM546 in acetonitrile is shown in Fig. 7. There is no change in the shape of the fluorescence spectra which suggests no exciplex formation. Absorption spectra even at the highest concentration of PM546 can be reproduced by the sum of the PM597 and PM546 spectra, indicating no ground state complex formation. The bimolecular quenching constant $k_{\mathrm{q}}$ is estimated using the Stern-Volmer equation, 


$$
I_{0} / I=1+k_{\mathrm{q}} \tau_{0}[\mathrm{PM} 546]
$$

where $I_{0}$ and $I$ are the fluorescence intensities in the absence and the presence of the quencher and $\tau_{0}$ is the fluorescence lifetime of PM597, $4.27 \mathrm{~ns}$ [15] in the absence of the quencher. The $I_{0} / I$ versus $[$ PM546] plot is observed to be linear. Linear regression analysis resulted in a bimolecular quenching constant of $2.6 \times 10^{10} \mathrm{dm}^{3} \mathrm{~mol}^{-1} \mathrm{~s}^{-1}$.

(Fig. 7)

\subsection{Effect of PM546 addition}

To rationalize the higher PM597 photodegradation rate and PM597 fluorescence quenching upon PM546 addition, additional elementary reactions should be considered in the photodegradation model [5]. Additional processes to consider in PM597 photophysics are: (1) dipole-dipole interaction induced singlet-singlet energy transfer, (2) Dexter triplet-triplet energy transfer, (3) PM546 sensitized singlet oxygen generation and (4) excited state electron transfer from PM dyes to PM546. The singlet-singlet energy transfer mechanism can be ruled out since the $\mathrm{S}_{1}$ state energy of PM546 is much higher than those of the other PM dyes. Overlap between absorption of PM546 and fluorescence of PM597 (PM567) is negligible. The triplet yield of PM597 is not negligible [16]. The longer triplet state lifetime can make energy transfer possible. In order to evaluate the Dexter triplet-triplet energy transfer mechanism (2), DFT calculations were performed to determine $S_{0}$ and $T_{1}$ energies. Calculated total energies for the $S_{0}$ and $T_{1}$ states and the relative energies of the $T_{1}$ state are listed in Table 1 . The $T_{1}$ energy of PM567 is in

good agreement with the experimentally obtained value of $37.9 \mathrm{kcal} \mathrm{mol}^{-1}$ [17]. The $\mathrm{T}_{1}$ energy of PM546 is higher than those of PM567 and 597. Therefore, the triplet-triplet energy transfer is not a possible path. Since PM546 possesses a relatively high fluorescence yield in acetonitrile $\Phi=$ 0.93-0.95 [16,18] and deoxygenated PM597 exhibited accelerated photodegradation upon 
PM546 addition, PM546 sensitized singlet oxygen generation will be a minor path for PM dye degradation. Further validation of this was stable PM546 absorbance readings following the prolonged $532 \mathrm{~nm}$ irradiation of a $2.5 \times 10^{-5}$ M PM546 acetonitrile solution. On the basis of the fluorescence quenching experiment, electron transfer may occur from the excited state of PM597 to the ground state of PM546. The predicted standard free energy changes $\left(\Delta G^{\circ}\right)$ are displayed in Table 2. The $\Delta G^{\mathrm{o}}$ values were estimated using the Rehm-Weller equation

$$
\Delta G^{\mathrm{o}}=E\left(\mathrm{D} / \mathrm{D}^{+}\right)-E\left(\mathrm{~A} / \mathrm{A}^{-}\right)-E_{00}-e^{2} / \varepsilon r_{\mathrm{DA}}
$$

where $E\left(\mathrm{D} / \mathrm{D}^{+}\right)$and $E\left(\mathrm{~A} / \mathrm{A}^{-}\right)$are the half-wave oxidation and reduction potential for the donor and acceptor, respectively, $E_{00}$ is the excitation energy, $e$ is the electronic charge, $\varepsilon$ is the dielectric constant of the solvent, and $r_{\mathrm{DA}}$ is the separation between the donor and the acceptor. The $r_{\mathrm{DA}}$ is equated to the sum of the radii of the donor and acceptor which were calculated at the B3LYP/6-31G(d) level. The free energy changes were exoergic. The probability of electron transfer is dependent upon the orbital overlap between donor and acceptor. The LUMO orbital of PM dyes is mainly delocalized in the pyrromethene difluoroborate framework with $\pi$ character. The overlap of orbitals may be effective due to similar family structures, which results in efficient electron transfer,

$$
\mathrm{D}^{*}+\mathrm{PM} 546 \rightleftarrows\left[\mathrm{D}^{+} \ldots \mathrm{PM}^{2} 46^{-}\right] \rightleftarrows \mathrm{D}^{+}+\mathrm{PM} 56^{-}
$$

(D: PM567 or PM597)

followed by [10]

$$
\begin{array}{lll}
\text { PM546- } & \rightarrow & \text { PM546 }+\mathrm{O}_{2}^{-} \\
\mathrm{D}^{+}+\mathrm{O}_{2}^{-} & \rightarrow & \text { products } \\
\mathrm{D}^{+}+\mathrm{D} & \rightarrow & \text { products } \\
\text { PM546- D } & \rightarrow & \text { products }
\end{array}
$$


In nonpolar $n$-hexane, solvent stabilization of the ion pair is weaker resulting in a shift of the equilibrium in Eq. (10) towards reactants. The failure to form the ion-pair leads to deactivation of this photodegradation mechanism.

\subsection{Phosphorescence Quenching by PM546}

The observed decrease in PM567 and PM597 photostability upon PM546 addition is in marked contrast to the reported photostability enhancement upon C540 addition [8]. In the present experiment accelerated photodegradation predominates in the competition between enhanced dye photostability and accelerated dye photodegradation upon PM546 addition. An additive's ability to enhance PM dye photostability is attributed to singlet oxygen quenching $[1,6,7]$. The PM546 singlet oxygen quenching rate constant was determined by recording the $1270 \mathrm{~nm}$ phosphorescence decay profiles of an irradiated $5.6 \times 10^{-5} \mathrm{~mol} \mathrm{dm}^{-3}$ rose bengal/acetonitrile solution with varying PM546 concentration. The phosphorescence temporal decay profiles are shown in Fig. 8 with fitting curves by an exponential function $c_{0}+c_{1} \exp \left(-c_{2} \mathrm{t}\right)$ via weighted linear regression. Increasing phosphorescence decay rates are observed for

increasing PM546 concentration consistent with ${ }^{1} \mathrm{O}_{2}$ quenching by PM546. A ${ }^{1} \mathrm{O}_{2}$ quenching rate constant of $3.86 \pm 0.18(2 \sigma) \times 10^{7} \mathrm{dm}^{3} \mathrm{~mol}^{-1} \mathrm{~s}^{-1}$ was obtained from the Stern-Volmer plot of the apparent quenching rate constants vs. PM546 concentration in Fig. 9. The obtained value is close to that reported for PM567 in benzene [17]. The observation of accelerated PM dye photodegradation upon PM546 addition despite the significant ${ }^{1} \mathrm{O}_{2}$ quenching rate constant, suggests faster kinetics for PM546 electron transfer (Eq. (10)) rather than $\mathrm{PM} 546{ }^{1} \mathrm{O}_{2}$ quenching.

(Figs. 8, 9)

\section{Conclusions}


The PM567 and PM597 photostability dependence upon PM546 was investigated in solution by measuring absorption spectra following $532 \mathrm{~nm}$ laser irradiation. Photodegradation rates increased with increasing PM546 concentration. Fluorescence quenching of PM597 by PM546 was observed in acetonitrile. Electron transfer from the excited state of PM597 to the ground state of PM546 was considered as the mechanism responsible for the fluorescence quenching and the accelerated PM dye photodegradation. The singlet oxygen quenching rate

constant of PM546 in acetonitrile was determined to be $3.86 \pm 0.18(2 \sigma) \times 10^{7} \mathrm{dm}^{3} \mathrm{~mol}^{-1} \mathrm{~s}^{-1}$. This suggests that in addition to the singlet oxygen concerned photodegradation mechanism, photoinduced electron transfer between the dye and the additive, which also acts as a singlet oxygen quencher, must be considered.

\section{Acknowledgements}

The authors are grateful to Prof. T. Fujii of Shinshu University for his encouragement throughout this work.

\section{References}

[1] M.D. Rahn, T.A. King, Appl. Opt. 34 (1995) 8260.

[2] M. Canva, P. Georges, J.-F. Perelgritz, A. Brum, F. Chaput. J.-P. Boilot, Appl. Opt. 34 (1995) 428.

[3] W.N. Sisk, N. Ono, T. Yano, M. Wada, Dyes and Pigments 55 (2002) 143.

[4] G. Qian, Y. Yang, Z. Wang, C. Yang, Z. Yang, M. Wang, Chem. Phys. Lett. 368 (2003) 555.

[5] W.N. Sisk, W. Sanders, J. Photochem. Photobiol. A: Chem. 167 (2004) 185. 
[6] M.D. Rahn, T.A. King, A.A. Gorman, I. Hamblett, Appl. Opt. 36 (1997) 5862.

[7] M.S. Mackey, W.N. Sisk, Dyes and Pigments 51 (2001) 79.

[8] M. Ahmad, T.A. King, D.-K. Ko, B.H. Cha, J. Lee, Opt. Laser Tech. 34 (2002) 445.

[9] G. Jones II, S. Kumar, O. Klueva, D. Pacheco, J. Phys. Chem. A 107 (2003) 8429.

[10] M.J. Frisch, G.W. Trucks, H.B. Schlegel, G.E. Scuseria, M.A. Robb, J.R. Cheeseman, J.A. Montgomery, Jr., T. Vreven, K.N. Kudin, J.C. Burant, J.M. Millam, S.S. Iyengar, J. Tomasi, V. Barone, B. Mennucci, M. Cossi, G. Scalmani, N. Rega, G.A. Petersson, H. Nakatsuji, M. Hada, M. Ehara, K. Toyota, R. Fukuda, J. Hasegawa, M. Ishida, T. Nakajima, Y. Honda, O. Kitao, H. Nakai, M. Klene, X. Li, J.E. Knox, H.P. Hratchian, J.B. Cross, C. Adamo, J. Jaramillo, R. Gomperts, R.E. Stratmann, O. Yazyev, A.J. Austin, R. Cammi, C. Pomelli, J.W. Ochterski, P.Y. Ayala, K. Morokuma, G.A. Voth, P. Salvador, J.J. Dannenberg, V.G. Zakrzewski, S. Dapprich, A.D. Daniels, M.C. Strain, O. Farkas, D.K. Malick, A.D. Rabuck, K. Raghavachari, J.B. Foresman, J.V. Ortiz, Q. Cui, A.G. Baboul, S. Clifford, J. Cioslowski, B.B. Stefanov, G. Liu, A. Liashenko, P. Piskorz, I. Komaromi, R.L. Martin, D.J. Fox, T. Keith, M.A. Al-Laham, C.Y. Peng, A. Nanayakkara, M. Challacombe, P.M.W. Gill, B. Johnson, W. Chen, M.W. Wong, C. Gonzalez, J.A. Pople, Gaussian 03, Revision B.03, Gaussian, Inc., Pittsburgh PA, 2003.

[11] M. Ahmad, T.A. King, D.-K. Ko, B.H. Cha, J. Lee, Opt. Comm. 203 (2002) 327.

[12] K. Kang, W.N. Sisk, M. Yasin, F. Farahi, J. Photochem. Photobiol. A: Chem. 121 (1999) 133.

[13] R.D. Scurlock, P. R. Ogilby, J. Photochem. Photobiol. A: Chem. 72 (1993) 1.

[14] M.A.J. Rodgers, J. Am. Chem. Soc. 105 (1983) 6201.

[15] J.B. Prieto, F.L. Arbeloa, V.M. Martínez, T.L. Arbeloa, I.L. Arbeloa, J. Phys. Chem. A. 108 (2004) 5503.

[16] R.Y. Lai, A.J. Bard, J. Phys. Chem. B 107 (2003) 5036. 
[17] A.A. Gorman, I. Hamblett, T.A. King, M.D. Rahn, J. Photochem. Photobiol. A: Chem. 130 (2000) 127.

[18] F.L. Arbeloa, T.L. Arbeloa, I.L. Arbeloa, J. Photochem. Photobiol. A: Chem. 121 (1999) 177.

\section{Figure Captions}

Fig. 1 Changes in the absorption spectra of $1 \times 10^{-5} \mathrm{~mol} \mathrm{dm}{ }^{-3}$ PM597 acetonitrile solution as a function of laser pulses.

Fig. 2 Photodegradation of $1 \times 10^{-5} \mathrm{~mol} \mathrm{dm}$ pyrromethene dye solutions, where $\mathrm{A} / \mathrm{A}_{0}$ designates the absorbance maximum normalized to the absorbance maximum at 0 pulses. ( $\Delta$ ) PM597 in $n$ hexane, (०) PM567 in acetonitrile, ( $\square$ ) PM597 in acetonitrile.

Fig. 3 Least-Squares fit of PM-597 concentration vs. number of pulses (t) to Eq. 7. (o) $n$-hexane solution and ( $\square$ ) acetonitrile solution. Solid lines show the linear fits. Note: initial pulses are fitted for acetonitrile solutions.

Fig. 4 Photodegradation of mixtures of $1.0 \times 10^{-5} \mathrm{~mol} \mathrm{dm}^{-3} \mathrm{PM}(567$ or 597$)$ and $2.5 \times 10^{-5} \mathrm{~mol} \mathrm{dm}^{-}$ ${ }^{3}$ PM546.

(a) Absorption spectra of acetonitrile solutions of $1.0 \times 10^{-5} \mathrm{~mol} \mathrm{dm}^{-3}$ PM567, $1.0 \times 10^{-5} \mathrm{~mol} \mathrm{dm}^{-3}$ PM597, 2.5×10 $0^{-5} \mathrm{~mol} \mathrm{dm}^{-3}$ PM546.

(b) PM597 and PM567 normalized absorbance decay:

( $\Delta$ ) PM597 absorbance of $n$-hexane solution of $1.0 \times 10^{-5} \mathrm{~mol} \mathrm{dm}^{-3}$ PM597

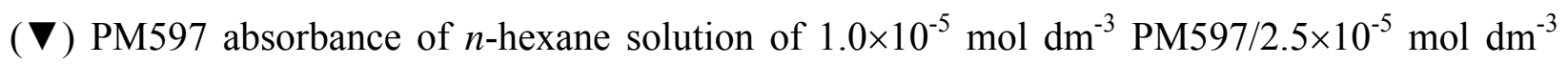
PM546

(口) PM597 absorbance of acetonitrile solution of $1.0 \times 10^{-5} \mathrm{~mol} \mathrm{dm}^{-3}$ PM597 
(ש) PM597 absorbance of acetonitrile solution of $1.0 \times 10^{-5} \mathrm{~mol} \mathrm{dm}^{-3} \mathrm{PM} 597 / 2.5 \times 10^{-5} \mathrm{~mol} \mathrm{dm}^{-3}$ PM546

(०) PM567 absorbance of acetonitrile solution of $1.0 \times 10^{-5} \mathrm{~mol} \mathrm{dm}^{-3}$ PM567

(•) PM567 absorbance of acetonitrile solution of $1.0 \times 10^{-5} \mathrm{~mol} \mathrm{dm}^{-3} \mathrm{PM} 567 / 2.5 \times 10^{-5} \mathrm{~mol} \mathrm{dm}^{-3}$ PM546

(c) PM546 normalized absorbance decay:

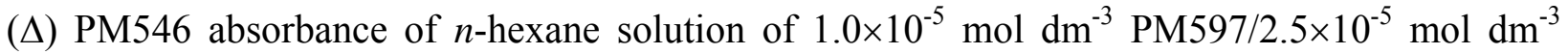
PM546

(口) PM546 absorbance of acetonitrile solution of $1.0 \times 10^{-5} \mathrm{~mol} \mathrm{dm}^{-3} \mathrm{PM} 597 / 2.5 \times 10^{-5} \mathrm{~mol} \mathrm{dm}^{-3}$ PM546

(०) PM46 absorbance of acetonitrile solution of $1.0 \times 10^{-5} \mathrm{~mol} \mathrm{dm}^{-3} \mathrm{PM} 567 / 2.5 \times 10^{-5} \mathrm{~mol} \mathrm{dm}^{-3}$ PM546

Fig. 5 Plots of absorbance ratios after 36,000 laser pulses vs. PM546 concentration. (O) PM597/PM546 in acetonitrile, () PM567/PM546 in acetonitrile.

Fig. 6 Oxygen dependence of PM597 photodegradation. (०) deoxygenated and (•) ambient air $n$ hexane solution, $(\Delta)$ deoxygenated and ( $\boldsymbol{\Delta})$ ambient air acetonitrile solution and $(\boldsymbol{\nabla})$ ambient air PM597/PM546 (1:1) acetonitrile solution.

Fig. 7 Fluorescence quenching of PM597 by PM546 in acetonitrile. The PM546 concentrations are 0 (solid line), $1.8 \times 10^{-3}$ (dotted line) and $2.7 \times 10^{-3}$ (dashed line) $\mathrm{mol} \mathrm{dm}{ }^{-3}$.

Fig. 8 Time-resolved ${ }^{1} \mathrm{O}_{2}$ phosphorescence following 532 irradiation of rose bengal/acetonitrile solution with varying PM546 concentration. 
Fig. 9 Stern-Volmer plot of the apparent rate constant vs. PM546 concentration. 
Table 1

Calculated total energies for the $S_{0}$ and $T_{1}$ states in hartrees and the relative energies of the $T_{1}$ state $E_{\mathrm{T}}$ in $\mathrm{kcal} \mathrm{mol}^{-1}$

\begin{tabular}{ccccccc}
\hline & \multicolumn{3}{c}{$\mathrm{HCTH} / 3-21 \mathrm{G}$} & \multicolumn{3}{c}{$\mathrm{B} 3 \mathrm{LYP} / 3-21 \mathrm{G}(\mathrm{d})$} \\
\cline { 2 - 6 } & $\mathrm{S}_{0}$ & $\mathrm{~T}_{1}$ & $E_{\mathrm{T}}$ & $\mathrm{S}_{0}$ & $\mathrm{~T}_{1}$ & $E_{\mathrm{T}}$ \\
\hline PM546 & -873.1806645 & -873.1190955 & 38.61 & -873.2061878 & -873.1446925 & 38.59 \\
PM567 & -1029.617821 & -1029.557958 & 37.56 & -1029.616355 & -1029.556248 & 37.72 \\
PM597 & -1186.020021 & -1185.963281 & 35.60 & -1185.996168 & -1185.938160 & 36.40 \\
\hline
\end{tabular}

Table 2

Photochemical and electrochemical properties of PM dyes.

\begin{tabular}{ccccc} 
& $E\left(\mathrm{D} / \mathrm{D}^{+}\right) / \mathrm{V}^{\mathrm{a}}$ & $E\left(\mathrm{~A} / \mathrm{A}^{-}\right) / \mathrm{V}^{\mathrm{a}}$ & $E_{00} / \mathrm{eV}$ & $\Delta G^{\mathrm{o}} / \mathrm{eV}$ \\
\hline PM546 & +1.22 & -1.18 & 2.52 & - \\
PM567 & +1.02 & -1.29 & 2.41 & -0.17 \\
PM597 & +1.01 & -1.24 & 2.38 & -0.15 \\
\hline
\end{tabular}

${ }^{\mathrm{a}}$ Ref. [9]. 


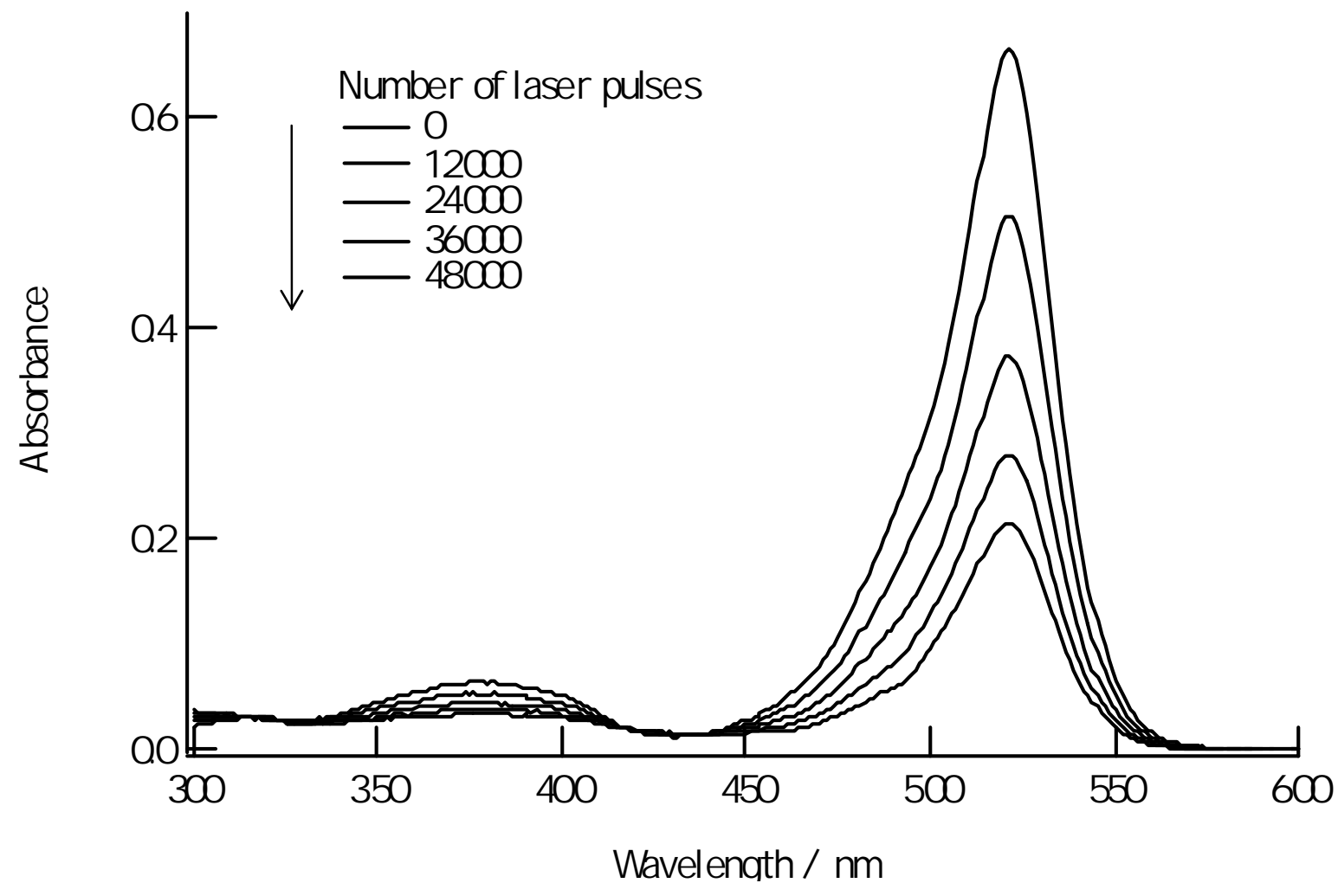

Fig. 1 


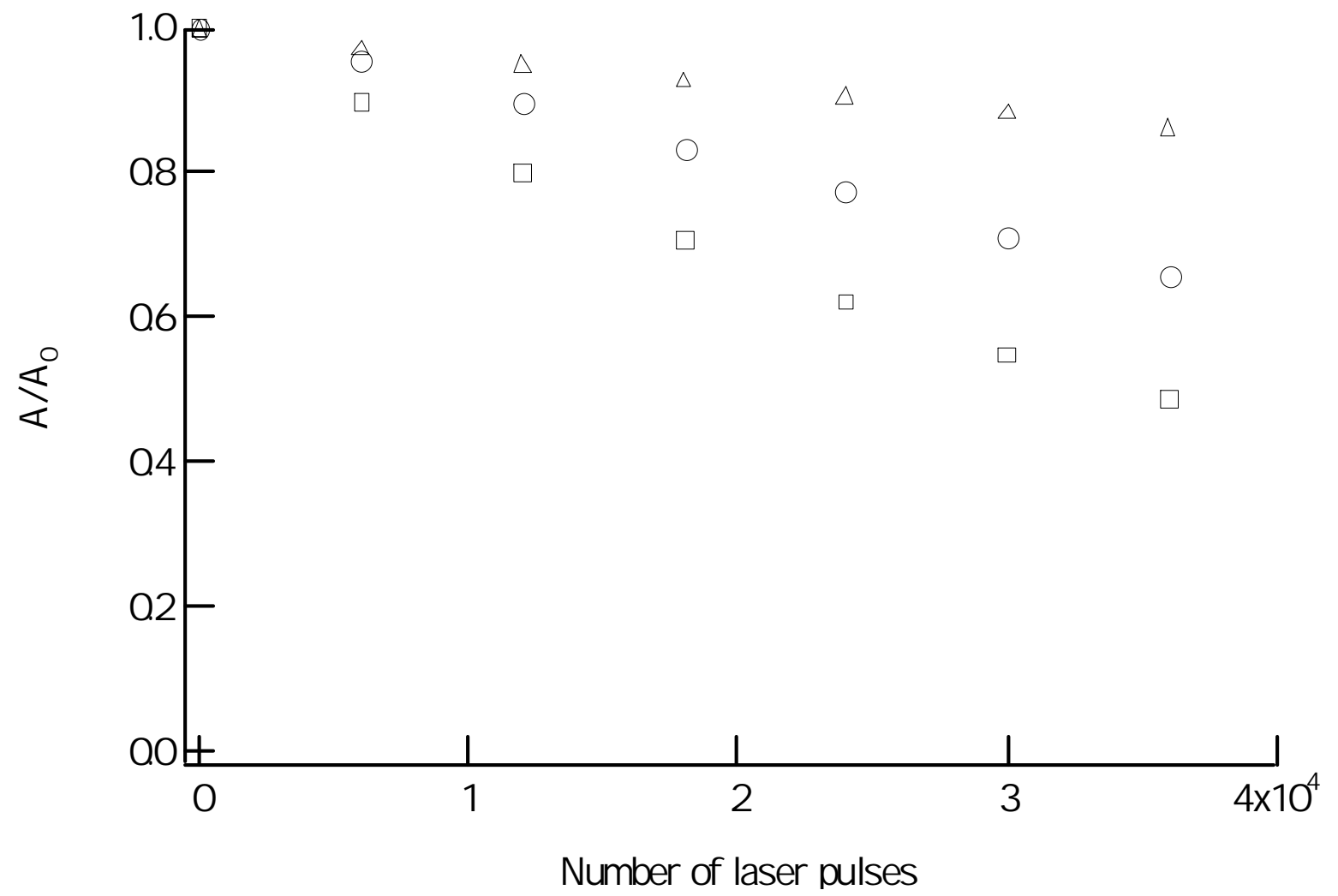

Fig. 2 


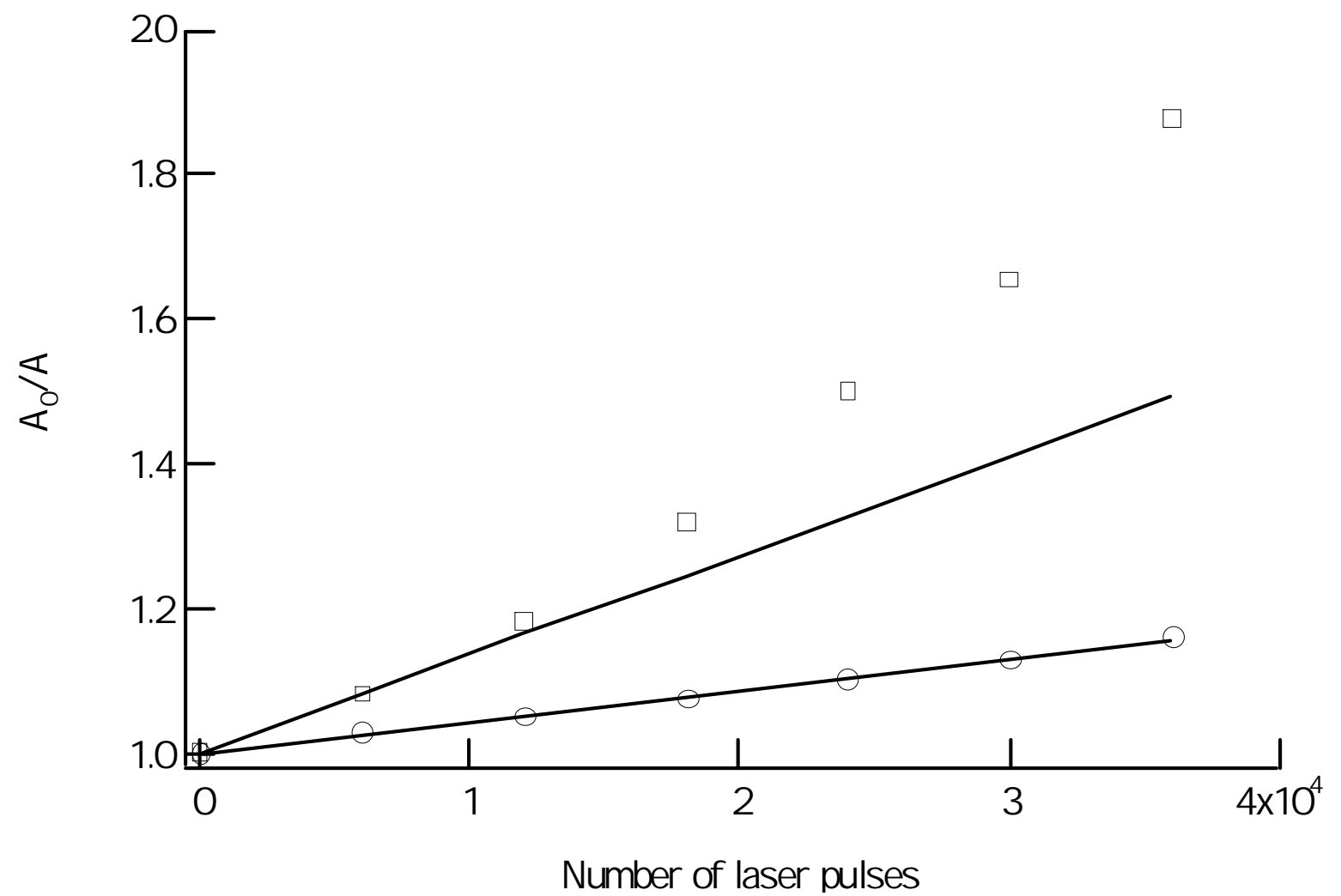

Fig. 3 


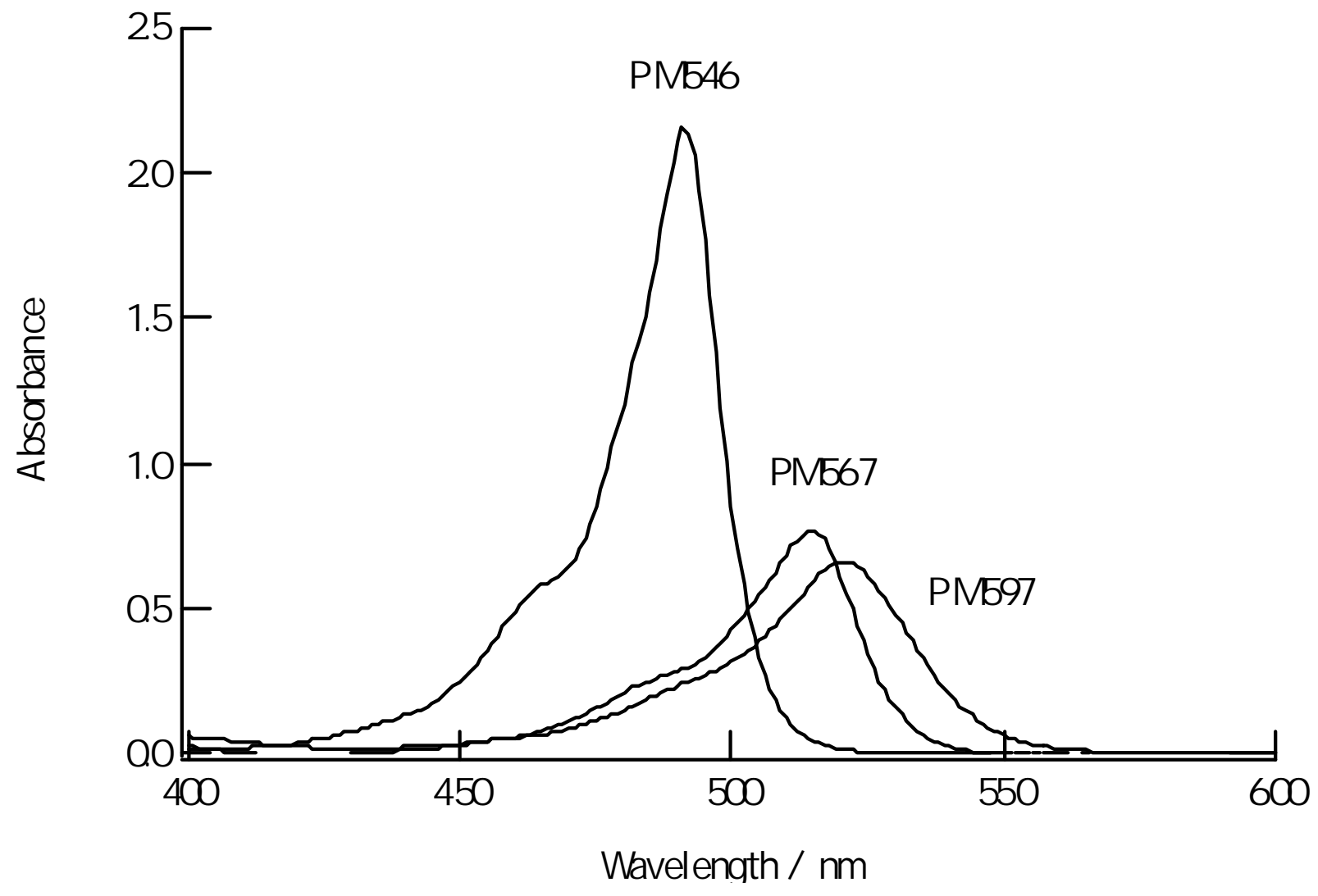

Fig. 4(a) 


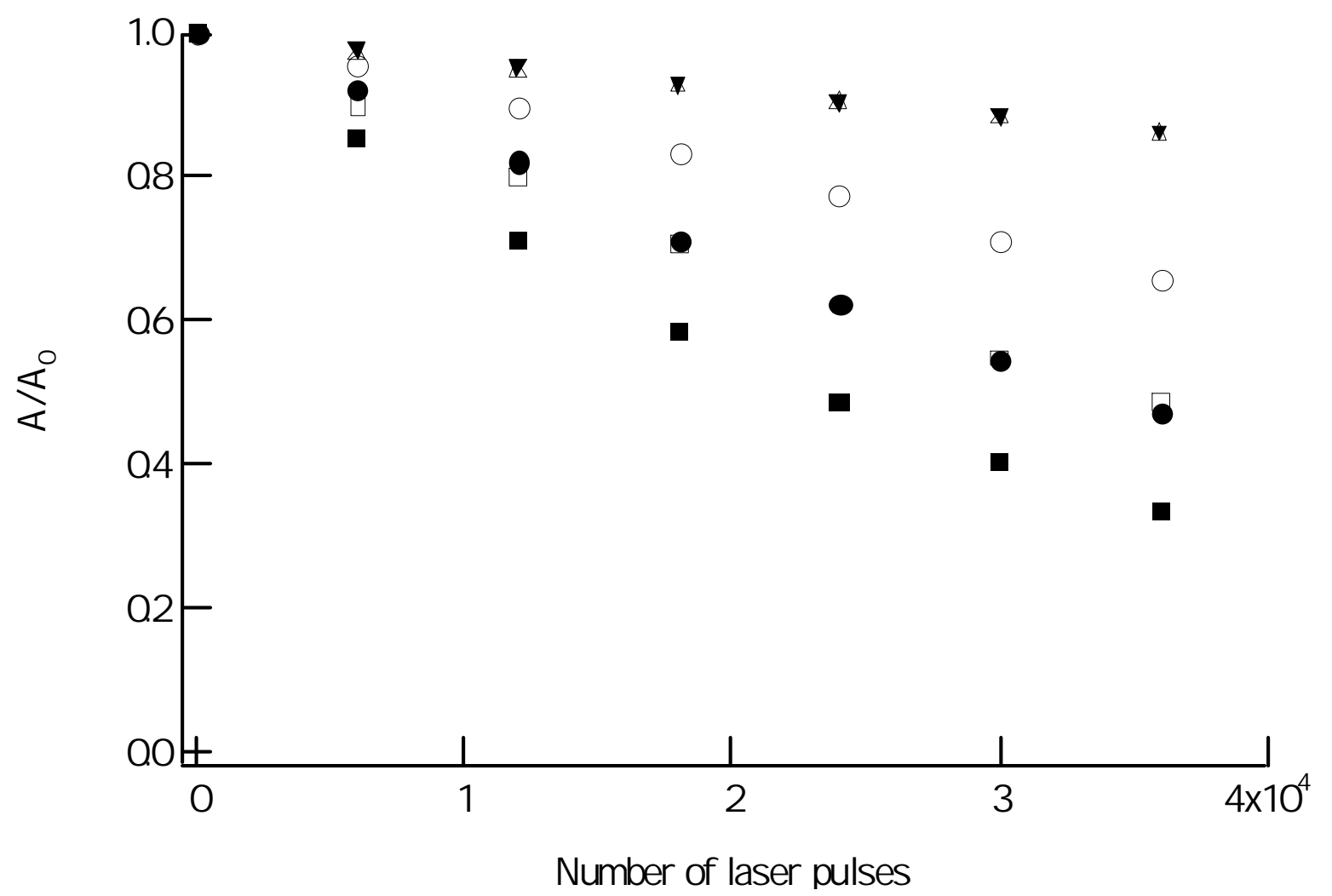

Fig. 4(b) 


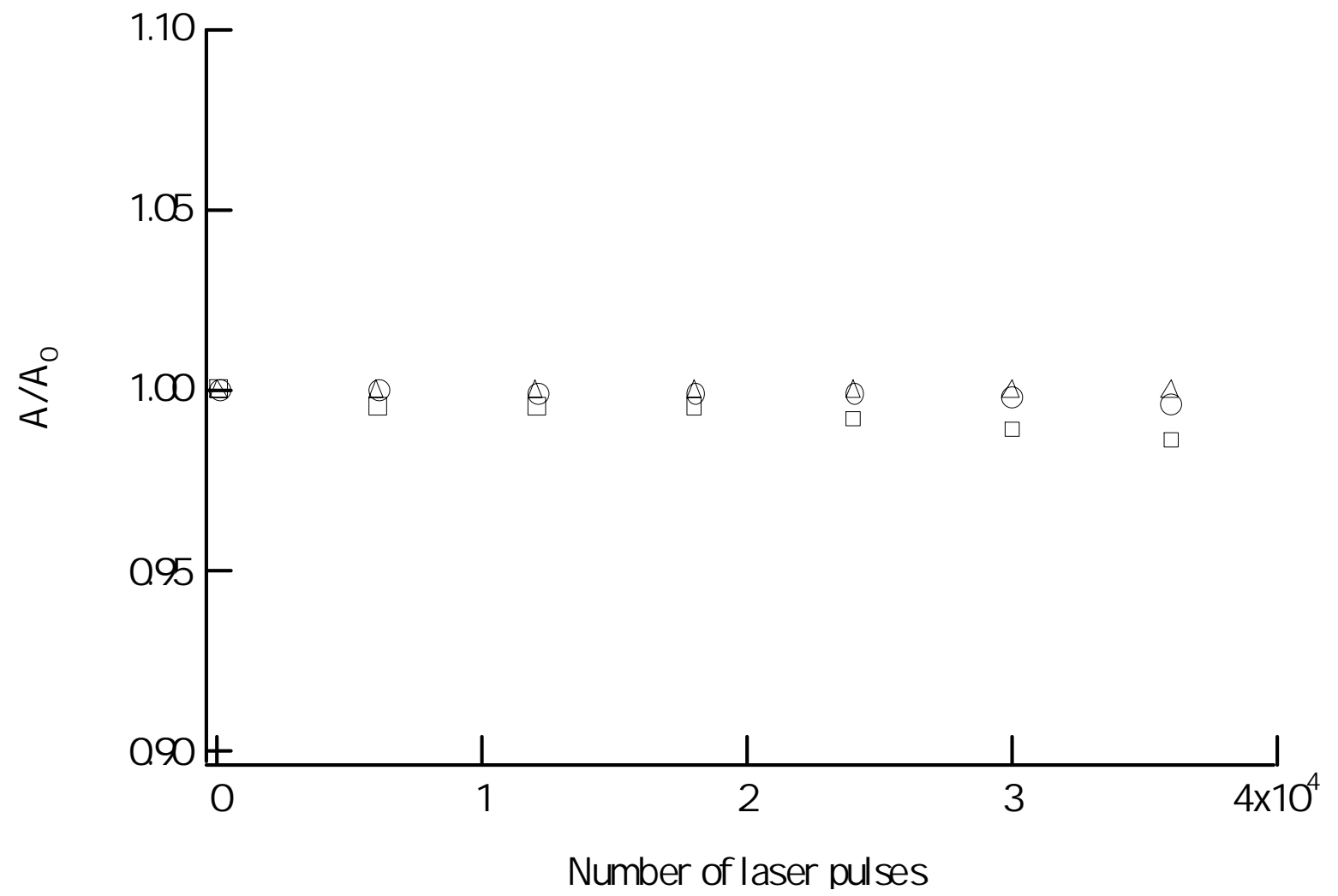

Fig. 4(c) 


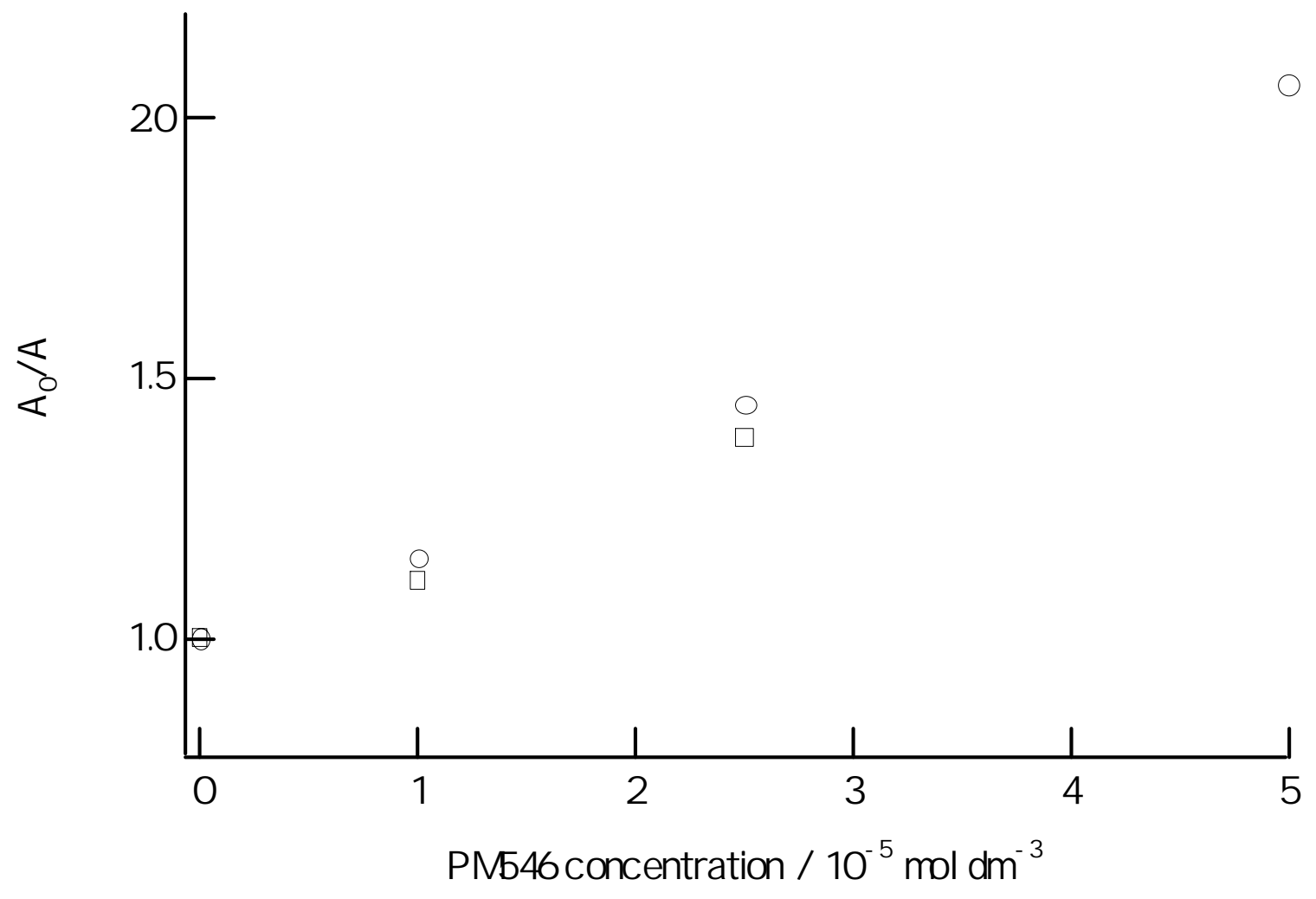

Fig. 5 


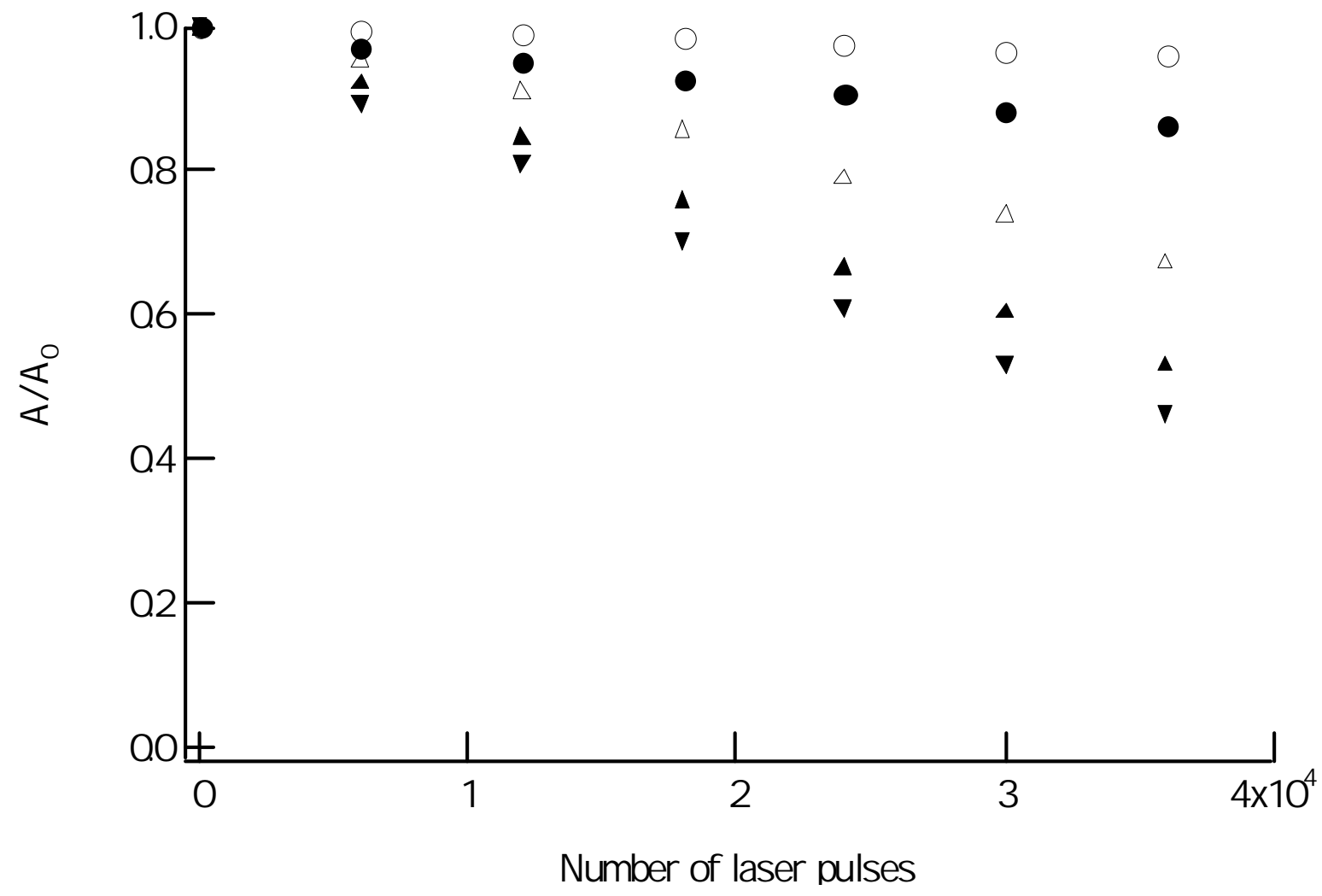

Fig. 6 


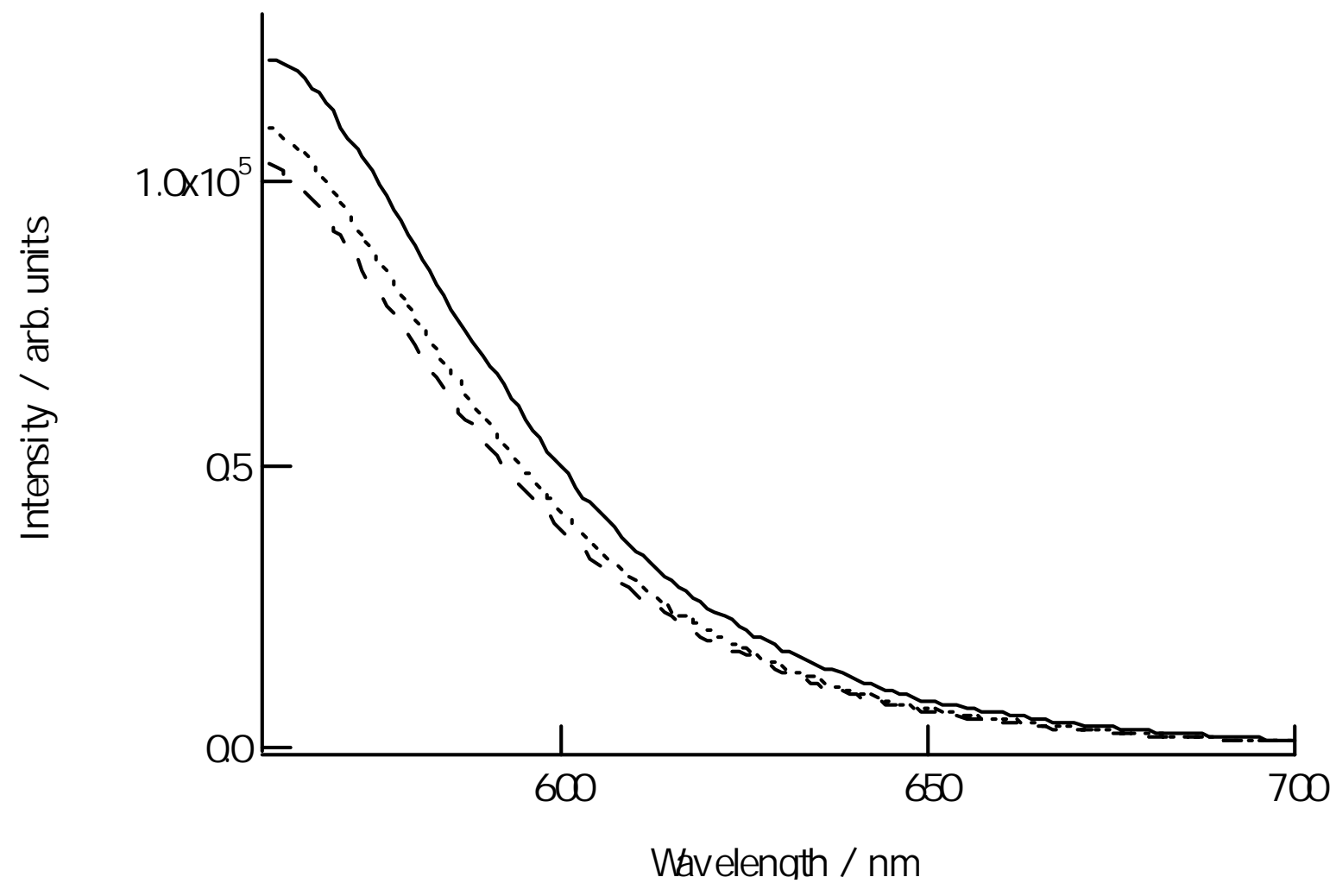

Fig. 7 


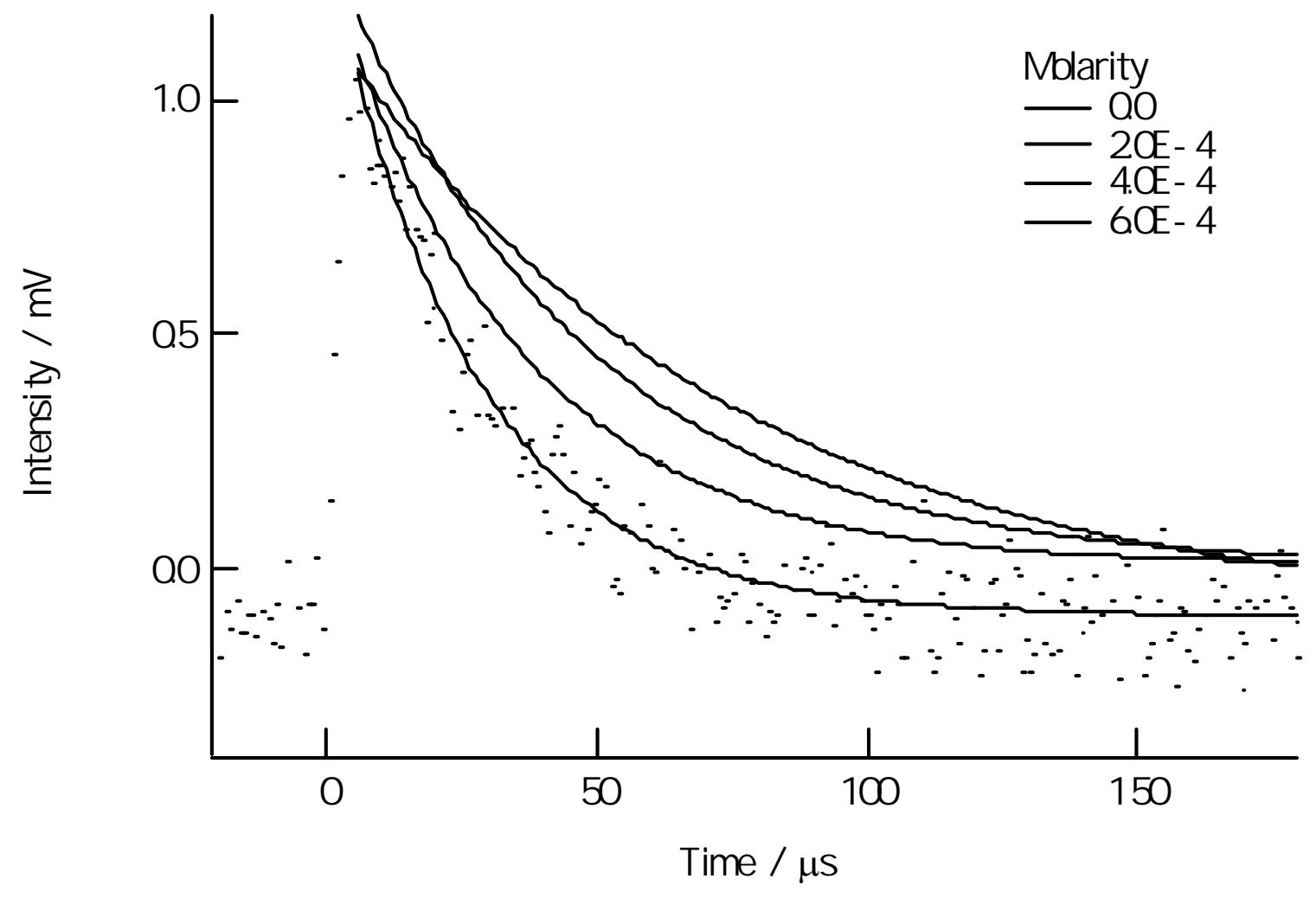

Fig. 8 


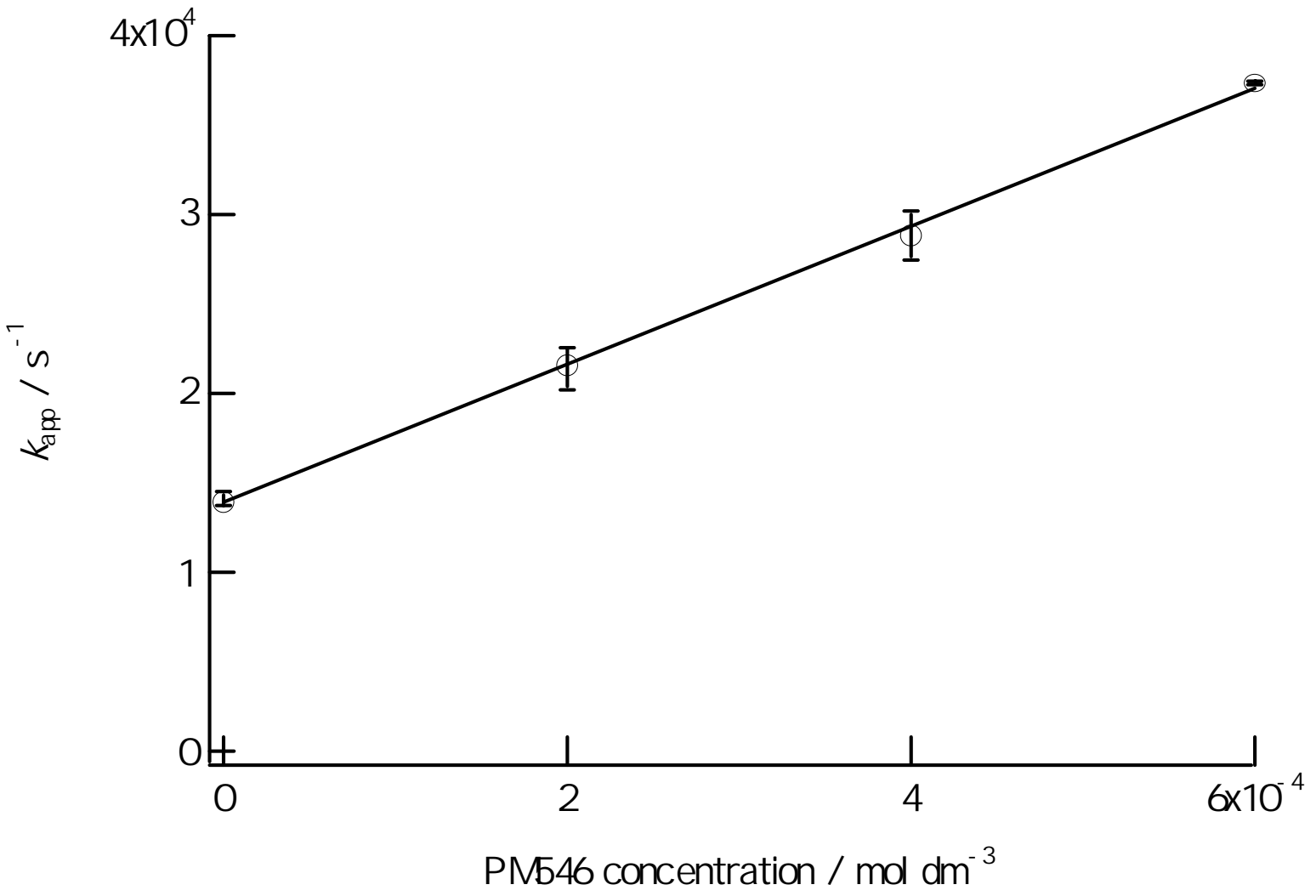

Fig. 9 